ESCENA

Revista de las artes
Publicación semestral. ISSN 2215-4906

Volumen 81 - Número 1

Julio - Diciembre 2021

\title{
Un Bolero \\ (una vez y otra vez)
}

Alex Condori Negrete

DOI 10.15517/es.v81i1.47289

(c) (i) $(-)$ Esta obra está bajo una licencia Creative Commons By NC ND Reconocimiento-No comercial-Sin Obra Derivada 
Obra artística

\title{
Un Bolero (una vez y otra vez)
}

\author{
Alex Condori Negrete ${ }^{1}$ \\ Estudiante de Artes Dramáticas \\ San José, Costa Rica
}

Recibido: 04 de enero de $2021 \quad$ Aprobado: 16 de marzo de 2021

1 Bachiller en Sociología por la Universidad Nacional de Costa Rica. Estudiante de Licenciatura en Artes Dramáticas en la Universidad de Costa Rica. ORCID: 0000-0002-1806-4198. Correo electrónico: alexcnbolcnbol27@gmail.com 
Dedicatoria

Este texto dramático es dedicado a la dramaturga Roxana Campos, artista, maestra y amiga que siempre me impulsó a soñar. Vuela alto querida maestra. 


\section{Personajes:}

DiEGo: adulto mayor de 75 años.

AdriAna: mujer de 30 años.

DoctoR: hombre de 40 años.

CÉSAR, VOZ EN OFF: adulto mayor amigo de Diego.

RADIO: vOZ en off.

(Entra Diego y enciende una radio).

RADIO El bolero, originario de Europa, fue traído por los españoles; primero se instauró en Cuba, para luego llegar a otras tierras. Es un género que nos denota nostalgia, una que se funda en el mito del paraíso perdido, en el que las cosas eran mejores, cuando las ciudades eran más habitables y el amor era el motor de la sociedad. Para otros, sin embargo, los mitos del milagro y de la región llena de amor ocultan la realidad de miseria, explotación y el abandono que ha caracterizado a América Latina. A continuación, "Es Imposible" de Ray Tico.

(Suena "Es Imposible" de Ray Tico).

DiEGo En ninguna fiesta puede faltar un buen bolero, de esos llenos de copas y amaneceres románticos.

CÉSAR EN OFF No hay nada más rico que bailar hasta que amanezca.

DIEGO Nosotros ya estamos viejos, solo podemos bailar hasta las ocho de la noche.

CÉSAR EN OFF Vos estarás viejo, yo apenas voy por mis 75 primaveras.

Diego Recordá que hoy es el cumpleaños de Adri. (En secreto). Cumple 30 años y quedamos de vernos en la casa de Jorge para la fiesta sorpresa. Él me va a recoger en la parada que esta acá cerquita. ¿Vos te llegás a la casa de mi hijo o necesitás que te llevemos?

CÉSAR EN OFF Tranquilo, yo llego.

Diego Perfecto, yo llevo todo lo necesario, el mejor regalo. (Levanta la bolsa que tiene en la mano).

ESCENA. Revista de las artes, 2021, Vol. 81, Núm. 1 (julio-diciembre), pp. 509-529 
CÉSAR EN OFF Querés mucho a Adri, ¿verdad?

Diego ¡Cómo no quererla!... a veces es un poco amargada con la familia, siempre pelea con sus hermanos y conmigo, dice que soy un viejo añejo, que tengo que dejar de pensar que el gobierno lo va a resolver todo y que es normal que un hombre ande con otro hombre y al revés también, (silencio) o sea, que una mujer ande con otra mujer, la verdad no la entiendo, dice que hay que promulgar la paz y el amor... Tendencias hippies de los años setenta, luego yo soy el viejo, siempre que está viendo el noticiero, se enoja y se pone de un humor, pelea con el presidente, el presentador de deportes y hasta con la ministra de Hacienda, ahí se pasa horas y horas peleando con el televisor, no entiendo dónde queda el "amor" y "la paz"...

CÉSAR EN OFF Imagino que discuten mucho por eso.

DIEGo No, no, nosotros no discutimos, nosotros dialogamos, yo la quiero así, con ese ímpetu de lucha.

CÉSAR EN OFF ¿Hace cuánto que no ves a tus otros hijos?

(Silencio).

DIEGo Ellos están demasiado ocupados... pero hoy tenemos la excusa perfecta para compartir en familia, ya que mi niña está llegando a su tercera década y eso hay que celebrarlo en grande, en familia. (Explicando el plan). Vea, César, la idea es que nosotros vamos a llegar primero y alistaremos la casa. Una vez que todo esté listo, vos tenés que llamar a Adri para decirle que me siento muy mal y que no puedo levantarme, para que Adriana se venga corriendo a la casa de Jorge y una vez que entre, salimos y le cantamos el bolero de Julio Jaramillo... (Empieza a moverse por el espacio, mientras canta y baila).

(Cantando).

"En el silencio de esta noche hermosa,

en el silencio de esta noche hermosa"2.

(Entra Adriana, se quita el abrigo, el sombrero y lo ponen sobre un perchero).

Adriana Hola Diego... (Camina hacia él y le revisa la temperatura). ¿Cómo has seguido?

2 "Felicitación", canción de Julio Jaramillo (1935-1978).

ESCENA. Revista de las artes, 2021, Vol. 81, Núm. 1 (julio-diciembre), pp. 509-529 
Diego Hola mi amor, pues me siento mejor. (Esconde la bolsa que tiene en su mano).

Adriana Se nota, te ves mejor que esta mañana.

DIEGO ¿Cómo estás?

AdRIANA Bien, un poco cansada por el trabajo.

Diego Lo importante es que tenés trabajo, el cansancio pronto va a pasar, con tal de que descansés un poco.

AdRIANA ¿Ya te tomaste los medicamentos?

Diego Sí, me los tomé a la hora que me dijiste, incluso los que no me gustan.

Adriana (Ríe). Recordá que tu salud es muy importante, así que si te sentís mal tenés que avisarnos.

Diego Bueno... a veces me dan pequeños dolores de cabeza, pero nada de qué preocuparse.

AdRIANA Tendremos que decirle al doctor que te revise de nuevo.

DIEGo No, no, seguro pronto se me pasará. Son muy pequeños los dolores de cabeza, además, los hospitales huelen muy mal, la gente parece muerta y una persona tan viva como yo no puede pasar mucho tiempo en lugares como ese.

AdRIANA Diego, tranquilo no te voy a llevar a ningún hospital y no te va a pasar nada por una revisión de rutina.

Diego Yo estoy bien, estoy como un roble, un poco viejo, pero un roble al fin. A mí los hospitales no me gustan, no te atienden bien, apenas te miran por encimita y te manda acetaminofén, te dicen que guardés reposo y ya, mejor me quedo aquí con vos...

Adriana Está bien, pero necesito que te cuidés, que te tomés los medicamentos y te acostés temprano. ¿Trato hecho?

Diego Trato hecho.

AdRIANA Recordá que debés tomarte los medicamentos a tiempo. La tableta blanca a la 10 de la mañana, la verde a las 2 de la tarde y la verde clarita a las 8 de la noche. Igual yo voy a estar pendiente de que no se te olvide nada, pero por si acaso, vos también tenés que acordarte. ¿Entendido? 
Diego Está bien, hija. (Suena la bocina de un carro; Diego tropieza).

Adriana Diego, Diego ¿Estás bien?

Diego ¿Escuchaste ese sonido?

AdRIANA ¿Cuál?

Diego (Desorientado). Nada... ¿Y vos cómo te has sentido el día de hoy? ¿No te sentís diferente, como más cansada por la edad?

AdRIANA Me siento más cansada.

Diego Ajá.

AdRIANA Pero es por el trabajo, mi jefe ya me tiene harta, cree que puede disponer de mi tiempo las 24 horas.

Diego Sí, pero... ¿no hay algo más? No sé, cómo si la Tierra ya le hubiera dado una vuelta al Sol.

AdriAna Yo siento que la Tierra ya le ha dado como 50 vueltas al Sol al mismo tiempo y el tiempo se ha ensañado conmigo. (Levanta una camisa de Diego).

Diego No, no, yo te estoy hablando de....

AdRIANA Diego, por favor, lo único que te pido es que mantengás el orden, no puede ser que a cada rato hay que recoger tus cosas tiradas, si seguimos así no me va a dar tiempo de hacer nada y hay muchas cosas que hacer aquí. Por favor, ¿podés tener un poco de consideración?

Diego Está bien, está bien no vuelve a pasar...

ADRIANA Esto no puede continuar así, si querés seguir viviendo en este lugar necesito que me colaborés más, además lo único que tenés que hacer es estar ahí, sentado. Podés ver la televisión o escuchar música. ¿Por qué mejor no te acostás un rato?

Diego Recordá que hoy voy para la casa de Jorge.

ADRIANA Cierto, hoy viene Jorge.

Diego Sí, (baja el tono de la voz) hoy todos nos quedamos en la casa de él.

AdRIANa ¿Cómo?

ESCENA. Revista de las artes, 2021, Vol. 81, Núm. 1 (julio-diciembre), pp. 509-529 
Diego (Duda). Ehhhhh...

AdRIANA ¿Qué dijiste?

Diego Que, que...que Marco también va llegar.

AdRIANA ¿Y para qué?

Diego Para compartir, para pasar un rato en familia. Hace mucho tiempo no lo veo, es bueno por lo menos vernos y cenar una vez al mes.

AdRIANA ¿Te aseguró que iba a llegar?

Diego Sí.

ADRIANA ¿De verdad?

Diego Bueno, dijo que haría todo lo posible por llegar.

AdriAna (Irónica). Ojalá llegue a la casa de Jorge antes de que la comida se acabe.

Diego Sí va a llegar.

Adriana Bueno, bueno.

Diego ¿Sabés? La familia es igual a un bolero, el cantante, su voz y la guitarra deben acompañarse. Siempre hay que acompañarse... ¿Recordás que de pequeñita te gustaba bailar? Podíamos ver los concursos de baile popular por horas y luego hacíamos una competencia, vos, tus hermanos, mi viejita y yo... ¿Qué te parece si bailamos un bolero? Vení, vení... (Empieza a bailar por el espacio).

Adriana Yo no sé muy bien los pasos del bolero.

Diego (Suena la canción "Piel Canela"3) Mirá, los pies casi siempre pegados al suelo y el movimiento de cadera al compás. Ahora viene pie izquierdo hacia adelante, ahora pie derecho hacia adelante sobrepasando el izquierdo, luego pie izquierdo adelante a la altura del derecho y se abre hacia la izquierda, después el pie derecho cierra y se junta con el izquierdo...

(El espacio se oscurece y una luz cae sobre ellos, el tiempo se detiene por un momento mientras ellos bailan).

3 "Piel canela", canción de Bobby Capó (1922-1989). 
Diego María y yo podíamos bailar por horas y horas... la extraño mucho... (Se quedan bailando hasta que termine la canción). ¿Qué hora es?

Adriana Son las 19:50.

Diego iSanto Dios, ya es tarde! Jorge dijo que pasaba a la parada por mí a las ocho de la noche, me tengo que alistar, no puedo salir así de la casa. ¿Has visto mi saco azul oscuro? (Sale del espacio). ¿Qué camisa creés que debo utilizar? ¡La corbata! ¿Cuál podría ponerme?

ADRIANA ¿Pero por qué querés ir tan arreglado?

Diego Recordá, hoy es un día de boleros. Además, llega Marco.

Adriana Claro... Marco.

Diego (Entra al espacio con varias camisas y corbatas). ¿Cuál de estas corbatas creés que combine mejor con mi camisa a cuadros? ¿Esta roja lisa, esta de Mickey Mouse o la negra?

AdRIANA La negra es más elegante.

Diego ¿Podrías ponerme un poquito de atención?

AdRIANA Ya te dije que se ve mejor la negra.

Diego Mejor voy a traer mi corbata de flores rojas. ¿Dónde dejé esa corbata? (Suena más fuerte la bocina de un carro. Diego se desvanece).

AdRIANA ¡Diego!

Diego Estoy bien, estoy bien.

AdRiAna Es mejor que te quedés acá, yo voy a traer lo que falta.

Diego Pero...

AdRIANA Nada de peros.

Diego Estoy bien.

Adriana (Le alcanza un vaso con agua). Tomate esto mientras voy a buscar lo que te vas a poner.

(Adriana sale).

ESCENA. Revista de las artes, 2021, Vol. 81, Núm. 1 (julio-diciembre), pp. 509-529 
Diego César, uno se da cuenta que ya está viejo cuando empezás a olvidar dónde dejás las cosas, por más que lo intentás la memoria no es la misma, te cuesta recordar una anécdota y la cara de un viejo amigo, todo es más lento, pareciera que el tiempo se ensaña con uno. Tal vez el tiempo hace que aprendamos a recordar más lento y con todo el cuerpo; intentamos reconstruir cada detalle, para no olvidar las cosas buenas que nos pasan. Por eso, mi querido amigo, muy bien lo decía María, si querés tener una memoria fuerte y sana, nunca dejés de repasar los pasos de un buen bolero, que son lentos, precisos y se queden en tu memoria.

CÉSAR EN OFF María era sabia.

Diego María es el recuerdo más lento que pasa por mi cuerpo.

CÉSAR EN OFF Entiendo, no hay que dejar de bailar para que la vejez no se lleve nuestros recuerdos.

Diego iiiExacto, César!!! Hablando de recordar, recordá que tenés que estar puntual en la casa de Jorge. Vos tenés que llamar a Adri para que llegue a "recogerme" (Diego hace un gesto de comilla con las manos). ¿Estamos claros?

CÉSAR EN OFF Ahí estaré sin falta.

DIEGO Hoy va ser una noche inolvidable. Ya verás, como en los viejos tiempos al ritmo de Ray Tico, toda la familia unida.

CÉSAR EN OFF Solo va a hacer falta María.

(Entra Adriana con una camisa, corbata y saco).

AdRIANA Esta camisa y corbata te van mucho mejor. (Empieza a vestirlo).

Diego Pero...

AdRIANa ¿Cómo te sentís?

DIEGO Bien.

AdRIANA Recordá comportarte bien en la casa de Jorge, intentá no discutir con él.

Diego Pero si nunca lo hago.

AdRIANA Diego.

ESCENA. Revista de las artes, 2021, Vol. 81, Núm. 1 (julio-diciembre), pp. 509-529 
Diego Solo a veces... lo que importa es que voy a poder ver a mis nietos que hace rato no los veo.

Adriana Tené cuidado con ellos, verdad. Te pueden hacer caer, no te pongás a jugar como un chiquito.

Diego Jueputa, ahora no puedo hacer nada. Mejor decile a Jorge que me amarren a una silla y yo los veo disfrutar desde ahí.

AdRIANa ¿Ves? No se te puede decir nada.

Diego $\quad$ Aún puedo hacer muchas cosas. Puedo ayudar en la casa y puedo cuidar a mis nietos. Creen que por ser un poco más viejo que ustedes, uno se vuelve un inútil en la casa. Pues no, yo tengo todas las ganas y las fuerzas para seguir trabajando, aun cuando ustedes me lo prohíban. No soy un inútil, no soy un inútil, antes de llegar a ser un estorbo prefiero morirme.

AdRIANA Diego, nadie está diciendo que seás un inútil. Lo único que te estoy pidiendo es que te cuidés.

DIEGO Lo voy hacer...

ADRIANA Solo no lo olvidés, ¿está bien?

Diego Sí.

(Suena el teléfono).

AdRIANA Andá saliendo, Diego. Seguro Jorge ya te está esperando en la parada. Recordá, del árbol de aguacates son 100 metros, ahí está la parada y nada de hablarle a desconocidos... (Sigue sonando el teléfono).

DiEgo Está bien, jnos vemos ahora!

(Suena la bocina de un carro fuerte y prolongado. Diego se sujeta de la puerta. Todo se congela y se escuchan voces en off).

AdRIANA EN OFF Jorge, ya Diego va de camino a la parada.

JORGE EN OFF ¿Cómo sigue?

ADRIANA EN OFF No entiendo a qué viene esa pregunta.

JORGE EN OFF Solo quiero saber cómo sigue.

ESCENA. Revista de las artes, 2021, Vol. 81, Núm. 1 (julio-diciembre), pp. 509-529 
AdRIANA EN off Aún con los dolores de cabeza, pero tranquilo, ya pronto lo vas a ver.

JORGE EN OFF ¿Qué es lo que tenés que hacer hoy?

ADRIANA EN OFF Voy a salir con unos amigos.

JORGE EN OFF ¿Y no has pensando llevar a tus amigos a la casa?

ADRIANA EN OFF Diego ya está listo y va de camino a esperarte.

JORGE EN OFF ¿No te parece una mejor idea festejar en casa? Ahí van a estar todos muy cómodos, pueden ver películas, él no les va a molestar y así no se queda solo en casa.

Adriana en off (Molesta). ¡Pero él va para tu casa!

JOREGE EN OFF Si quieren algo de privacidad, se encierran en tu cuarto y dejan al viejo viendo tele. Verás que él no los va a molestar para nada.

ADRIANA EN OFF ¿No vas a venir a llevarte a papá verdad?

JORGE EN OFF ¡NO!

AdRIANA EN OFF Me prometiste que hoy lo cuidarías.

JORGE EN OFF Lo sé, pero no puedo. Lo lamento.

AdRIANA EN OFF Esta es como la quinta vez que lo dejás plantado, él lleva meses esperando verte.

JORGE EN OFF A veces las cosas no se dan como esperamos.

AdRIANA EN OFF Hace días vengo planeando esta salida.

JORGE EN OFF LOS planes siempre cambian.

ADRIANA EN OFF Yo paso acá todo el día encerrada con él.

JORGE EN OFF Sos la menor, sos mujer, podés cuidarlo.

AdRIANA EN OFF Tengo una vida también. Hoy es el único día que puedo salir, además es mi cumpleaños...

JORGE EN OFF ¡Que egoísta! Preferís tu cumpleaños a la vida de papá.

AdRIANA EN OFF Paso todos los días con él. Solo dejame salir hoy, solo por hoy. 
JORGE EN OFF Hace más de un año te propusimos que lo enviáramos a un hogar de ancianos y fuiste la primera en oponerte.

AdRIANA EN OfF Pero, ¿cómo pensás mandarlo a un lugar de esos?... Es como si lo estuviéramos abandonando. Además, ahí los descuidan y en muchos lugares los maltratan.

JORGE EN OFF Pero va a estar con personas de su edad. Te aseguro que se va a sentir muy bien, encontrará amigos de su edad, ellos siempre tienen de qué hablar. De seguro hay una persona que lo cuida. Ahí él no va estar solo y nosotros podemos ir a visitarlo cuando tengamos tiempo. Ya no será más una preocupación.

ADRIANA EN OFF ¿De verdad pensás dejar a papá en un centro?

JORGE EN OFF ¿Entonces qué hacemos? Vamos a perder compromisos, empleos, amistades, por cuidarlo.

ADRIANA EN OFF ¿Y el dinero? No es gratis internar a papá en un hogar de ancianos. Sabés que el dinero que gano apenas me alcanza para vivir.

JORGE EN OFF También está el centro geriátrico.

AdRIANA EN OFF ¡Por Dios! ¿En qué estás pensando?

JORGE EN OFF Él sí me preocupa, pero también tengo una familia por la cual debo ocuparme. Además, es tu deber cuidarlo, imejor festeja el cumpleaños ahí con papá!

ADRIANA EN OFF ¿Qué querés que festeje? Que paso acá todo el día encerrada sin tener una vida, buscando mil maneras de que no le pase nada...

(Jorge cuelga el teléfono).

AdRIANA EN OFF ¿Aló?, ¿aló? iiiJorge!!! iiiJorge!!!

(Se escucha el frenazo de un carro. El ruido de la bocina desaparece. Diego cae al suelo. Adriana intenta reanimarlo un par de veces y, al no lograrlo, sale en busca de alcohol y algodón para despertarlo. El espacio cambia. Adriana se ve diferente).

AdRIANa (Le pasa el algodón por la nariz). ¡don Diego! ¡don Diego!

Diego (Aturdido). ¿Qué pasó?

AdRIANa Se desmayó.

ESCENA. Revista de las artes, 2021, Vol. 81, Núm. 1 (julio-diciembre), pp. 509-529 
Diego Tengo que irme. (Intenta levantarse).

AdRIANa No se mueva, quédese un rato en el suelo.

Diego (Intenta levantarse). Yo estoy bien, no te preocupés.

AdRIANA Hágame caso, quédese un rato en el suelo.

Diego Está bien...

AdRIANA ¿Qué fue lo que pasó? ¿Se mareó o se tropezó con algo?

DIEGO Nada me pasó, nada.

AdRIANa ¿Le duele algo? (Lo empieza a revisar).

Diego Ya te dije que no pasa nada. (Intenta levantarse nuevamente).

AdRIANA Mejor siéntese en esta silla. (Le alcanza una silla). Baje la cabeza, colocándola entre las piernas, así favorece la irrigación sanguínea cerebral.

Diego Qué no es nada, no es nada...

AdRIANA ¿Puede hacerme caso...?

Diego (Molesto). Está bien.

AdRIANA ¿Está seguro que no se siente mareado?

Diego iQué no estoy mareado! Pero si me quedo en esta posición, sí me voy a marear.

ADRIANA Solo es un rato.

Diego Me siento incómodo.

AdriAna Eso le va hacer bien a sus mareos. (Le alcanza el vaso con agua).

DIEGo No puedo tomar el agua de esta manera.

Adriana (Ríe). ¡Ay, Diego!

Diego Ves, luego uno es el viejo tonto, no entiendo por qué esa manía de cuidarme tanto.

Adriana Bueno... si ya se siente mejor, levántese lentamente y luego tome el agua.

DIEGo (Se levanta lentamente). ¿Vos no escuchaste ese sonido? 
AdRIANA No, no he escuchado nada... (Le revisa la presión).

Diego (Él la observa). ¿Sabés que tenés los ojos igual a los de María?... Sí, sos igualita. Tenés la misma sonrisa y las ganas de ayudar a los demás. Cuando enfermó, yo la cuidé. Nunca me despegaba de ella, pero poco a poco la situación se fue tornando más difícil, cada día iba olvidando más cosas. Cuando se me acercaba, me preguntaba que quién era yo. Yo le respondía que era un soldado y que la reina de esta ciudad me había mandado a protegerla de todos los peligros de este mundo. Ella me decía: "que dicha que mandaron a un muchacho tan guapo, pero yo puedo cuidarme sola". (Ríe). Era divertido, porque podíamos ir creando muchas historias juntos. Nos volvimos como dos niños a los cuales les gusta inventar cosas inimaginables. Viajábamos desde la Habana, Cuba, hasta la Cordillera de los Andes. Un día era Don Quijote de la Mancha junto a Dulcinea y al día siguiente ella era Evita Perón luchando por la libertad latinoamericana. Antes de dormirnos bailábamos un buen bolero, al compás de cuatro tiempos: el primer tiempo, uníamos la frente uno con el otro, ya con los cuerpos pegados movíamos la pelvis, en el segundo tiempo daba un paso rápido, en el tercero también y en el cuarto daba un paso más lento; todo esto mientras ella giraba lentamente hacia la izquierda, para volver a pegar la frente y cantarle. (Empieza a sonar "Contigo en la distancia4"). Cada vez era más difícil llevar el compás de cuatros tiempos, las historias se convertían en pesadillas y los encuentros en pleitos. Con el tiempo aprendí a bañarla, a limpiarla cuando lo necesitaba, curé cada una de sus heridas. ¿Sabés? Fuimos muy felices... entre más desgastada la veía, me preguntaba si realmente valía la pena llegar a ese deterioro, llegar a ese lugar donde te volvés un despojo humano, donde ya nadie quiere estar. El silencio y la soledad se vuelven un compañero de vida, te toca aprender a estar solo mientras los demás se divierten... ¡Qué irónico! Cuando sos joven buscás tener una vida digna, pero cuando llegás a viejo la perdés. Deberíamos exigir una vejez más digna o al menos una muerte digna. Nadie se merece llegar a viejo tan desgastado y olvidado. No es nada agradable depender de los demás, más si ellos no quieren ser parte de tu vida.

Adriana Siento mucho lo que pasó.

Diego Yo agradezco que vos me acogieras. Sé que siempre vas a estar junto a mí, ¿verdad?

4 “Contigo en la distancia", canción de César Portillo de la Luz (1922-2013).

ESCENA. Revista de las artes, 2021, Vol. 81, Núm. 1 (julio-diciembre), pp. 509-529 
Adriana (Silencio).

Diego Mi saco, ¿dónde está mi saco? Jorge está por llegar y yo sigo acá, se va a molestar.

AdRIANA Jorge acaba de llamar y me dijo que estaba un poco retrasado. Si quiere podemos hacer algo de comer mientras lo esperamos.

Diego ¿Y si llega antes de que terminemos de comer?

AdRIANA Puedo hacer algo rápido, como un picadillo de papa.

Diego Como los que hacía María; si quéres yo te ayudo...

AdRIANA No es necesario. (Empieza a buscar unos calmantes en la habitación).

DIEGO Jorge me dijo que llegaría puntual, seguro debe haberle pasado algo. Voy a llamarlo. (Busca su celular).

Adriana (Sigue buscando los calmantes). Ya casi empiezo a cocinar, en todo caso si no logro terminarlo y él llega, le pedimos que espere un rato, alisto la comida para que se la lleve... Es más, si quiere, para que esté más tranquilo, mejor lo llamo y le digo que no venga, que es mejor que se vaya directo a su casa, que nosotros llegamos más tarde, así usted come tranquilo.

Diego No, no es necesario. Ya es muy tarde, mejor me voy caminando y tal vez me lo tope en el camino.

AdRIANA Ya le dije que es mejor esperar, seguro está ocupado y por eso viene tarde.

DIEGo César me debe estar esperando... ¿¿Dónde está mi saco?!

AdRIANA Diego, no puede irse solo, le puede pasar algo.

Diego No me va a pasar nada.

AdRIANA Usted no puede salir así alterado. (Se para frente a la puerta).

Diego Yo soy una persona adulta.

AdRIANa Por lo mismo no puede salir solo a la calle.

Diego Me puedo cuidar solo... yo voy hacer lo que me dé la gana.

AdRIANA ¿Por qué mejor no se sienta un rato? 
Diego No quiero, lo único que quiero es ir a la casa de Jorge y hablar con César.

AdRIANa Eso no se va a poder.

(Diego empieza a tirar las cosas del lugar).

Diego No me va a pasar nada, no soy un niño. Lo único que quiero es salir de esta casa, quiero volver a tener mi libertad, donde yo decidía qué es lo que quería hacer.

AdRIANA Tranquilo, don Diego. (Le toma el brazo). ¿Por qué no mejor descansa un rato?

(Suena la bocina de un carro y Diego se desvanece).

AdRIANa iiidon Diego!!!

DIEGo Andate, andate, ya no quiero que estés en mi casa. Andate, yo puedo mantenerme solo. Yo no necesito a nadie, andate.

AdRIANA don Diego por favor, necesito ver si se encuentra bien.

Diego ¡Me voy, me voy! (Choca con las cosas de la casa).

AdRIANA ¿Qué está haciendo?

DIEGO ¡Me voy de esta casa! (Empieza a recoger con torpeza las cosas que le pertenecen).

AdRIANA don Diego... por favor, tenga cuidado, le puede pasar algo. ¡Se va a hacer daño! ¿No entiende que le puede pasar algo?

DIEGo Me quiero ir de esta casa.

AdRIANA Ya le dije que no va a salir.

DIEGO (Gritando). ¡Me estás privando de mi libertad!

AdRIANa Por favor, escúcheme. (Lo toma del brazo).

Diego iiiSuélteme!!!

(Adriana intenta detenerlo. Ambos forcejean).

(Entra el Doctor).

Doctor iiidon Diego!!! Se va a hacer daño. (Lo inmoviliza). 
AdRIANa Tenga cuidado, puede lastimarlo.

Doctor Es la única forma de detenerlo cuando se pone así.

Adriana (Al Doctor). ¿Dónde estaba?

Doctor Nos llamaron desde el ministerio, hay una emergencia. Pero, ¿qué fue lo que le pasó a don Diego?

ADRIANA Jorge volvió a cancelar la cita para visitarlo y usted sabe cómo se pone cuando pasa eso.

Doctor ¿Ya le puso algún calmante?

DIEGO (Sigue forcejeando). Necesito irme, me están esperando en la parada.

AdRIANA Ya no hay calmantes, no he encontrado ninguno...

Doctor En la gaveta de mi oficina hay algunos.

(Adriana sale del espacio).

Doctor don Diego, escúcheme, escúcheme. Usted está en un hogar de ancianos, respire, inhale por la nariz y exhale por la boca, inhale por la nariz y exhale por la boca, inhale por la nariz y...

Diego (Mira al Doctor). Jorge, jllegaste! Pensé que nunca llegarías, no te olvidaste de mí. (Se queda mirado al Doctor). ¡A festejar! ¡A festejar, que ya estamos completos! César, ¿por favor podés traer el queque que le compramos a Adriana?

Doctor don Diego, no puede levant....

DIEGO (Interrumpe y se levanta). Seguro Adri está a punto de llegar a la casa. (Abre la bolsa que tiene en su mano y saca un cubre bocas y se lo pone como si fuera un sombrero de cumpleaños. Le entrega uno al Doctor). Toma, este es tuyo. Apenas entre tu hermana, le cantamos. Listo. César, ¿ya tenés el queque con las velitas? (Gritando). ¡César! Adriana está a punto de llegar...

(Adriana entra con los calmantes. En ese momento, Diego empieza a cantar la canción de "Feliz Cumpleaños" de Julio Jaramillo. Mientras lo hace, va lanzando sus medicamentos como si fuera confeti. Le pone la mascarilla en su cabeza y le entrega su regalo).

Diego Te quiero, mi niña. 
Adriana (Confundida). Gracias...

DiEGO ¿Por qué esas caras largas? ¡A bailar! ¡A bailar! Que hoy es un día para festejar.

AdRIANA don Diego, por favor, necesitamos que nos escuche.

Diego No, no, hoy tenemos que festejar.

AdRIANA Diego...

Diego ¡Hay que festejarlo en familia...! (Baila).

Doctor don Diego, estamos en un hogar de ancianos.

Diego No, no, esta es tu casa, Jorge.

Doctor Esta es la casa de muchas personas.

Diego (Molesto). ¡Qué no! Esta es tu casa, Jorge. (Sigue bailando). Ustedes quieren hacerme creer que estoy loco y así deshacerse de mí y enviarme a uno de esos hogares. Yo los escuché.

Doctor Usted ya está en uno.

DIEGO (Deja de bailar lentamente). Mentira, mentira... quieren hacerme creer que estoy loco y así abandonarme como lo hicieron con mi María. Yo sé que ella ya estaba muy mal de salud, pero yo la cuidaba y estuve dispuesto a cuidarla hasta que se muriera, pero ustedes me convencieron que la dejara ir; yo no quería, ustedes dijeron que era lo mejor para ella... era la única que me entendía, me acompañaba, jugaba y soñaba conmigo... (Observa el lugar y poco a poco se va percatando de donde se encuentra. Su actitud cambia). ¿Qué fue lo que me pasó?

ADRIANA ¿Por qué mejor no toma asiento?

Diego Así estoy bien

AdRIANA Según los reportes de la ambulancia, usted se le tiró a un carro que venía por la avenida, traía un gorrito de cumpleaños y un regalo en su mano, que nunca soltó.

(Diego observa la bolsa que tiene en su mano). 
AdRiAna La ambulancia lo recogió y lo llevaron al hospital... Se quedó en el hospital unos días y nadie reclamó por usted, entonces lo trajeron para acá. Hasta el momento no sabemos por qué tomó esa decisión.

Diego ¿Cuánto tiempo llevo en este lugar?

DOctor Lleva aproximadamente un año y medio.

Diego ¿Y no buscaron a mis hijos?

Doctor Eso fue lo primero que hicimos, no logramos ubicarlos. Llegaron a esta casa unos meses después. Preguntaron cómo se encontraba usted y luego dieron dinero para su estadía; todos los meses dejan cosas, como ropa, paños, cepillo de dientes y demás artículos para usted.

DIEGO ¿Y no se quedan a saludarme?

(Silencio).

AdRIANA don Diego, ¿ya se siente mejor?

Diego Creo que sí.

AdRIANA Necesita comer algo antes de dormir.

DIEGO No tengo hambre.

AdRIANA Tiene que comer algo, por lo menos una sopa.

Diego En serio, no tengo hambre.

DOctor Bueno, por hoy se lo voy a dejar pasar. Le vamos a poner un poco de suero y calmantes para que se relaje, pero necesita comer algo mañana en la mañana, este tipo de ataques lo desgasta mucho.

Diego Está bien.

Doctor Adriana, ¿podés pasarme el suero y una varilla?

Adriana (Le pasa el suero). Ya no nos queda ninguna varilla. ¿Qué tal si usamos este perchero?

Doctor Sí, eso sirve. (Le pone la vía para el suero y lo deja colgando en el perchero). Vamos, don Diego, levante ese ánimo. 
AdriAna (Aparta al Doctor). Ellos siempre cancelan a último momento...

Doctor No podemos hacer nada, (Hacia Diego) don Diego, necesito que se relaje. Adriana y yo tenemos que ir a resolver una emergencia en la oficina, pronto llega otra enfermera. ¿Será que lo podemos dejar solo un momento?

Diego Sí.

Doctor Gracias. Vamos, Adri.

(Salen).

(Diego aún se ve desubicado, observa el lugar y luego enciende la radio).

RADIO El bolero es memoria y seguirá presente ya no como una moda, sino como un signo de identidad y como parte del patrimonio cultural de las y los latinoamericanos. El bolero es parte de nuestra historia y de las historias de todos nuestros abuelos. Hoy más que nunca, en medio de esta emergencia, no dejemos que nuestros boleros se desvanezcan. Reencontrémonos con nuestra historia, identidad y familia, es un tiempo importante para compartir...

(Empieza a sonar el bolero de Ray Tico "Es imposible")

Diego (Hablando con el perchero). Como te decía, César, en ninguna fiesta puede faltar un buen bolero, de esos llenos de copas y amaneceres románticos... Recordá que hoy es el cumpleaños de mi hija y lo vamos a festejar en la casa de Jorge. Adri es la soñadora de la familia, es la que alegra la casa. ¿Sabés que uno de sus sueños es viajar por el mundo?... No le contés a nadie, pero le acabo de comprar un pasaje para que se vaya a Cuba a escuchar los mejores boleros... Hoy es un día importante porque hace mucho tiempo que no compartimos en familia.

\section{Fin}

